\title{
Electrodeposition of Gold Nanoparticles on Electrochemically Reduced Graphene Oxide for High Performance Supercapacitor Electrode Materials
}

\author{
Zhihao $\mathrm{Yu}^{1^{*}}$, Suqin Sun ${ }^{2}$ and Mingxian Huang ${ }^{3 *}$ \\ ${ }^{1}$ University of Shanghai for Science and Technology (The Public Experiment Center), NO.516 \\ Jungong Road, Shanghai, China. \\ ${ }^{2}$ Shanghai municipal Hospital of Traditional Chinese Medicine, NO. 274 Zhijiang mid Road, \\ Shanghai, China. \\ ${ }^{3}$ University of Shanghai for Science and Technology (The college of science), NO.516 Jungong Road, \\ Shanghai, China. \\ E-mail: zhihaoyuusst@gmail.com
}

doi: $10.20964 / 110448$

Received: 7 February 2016 / Accepted: 26 February 2016 / Published: 1 April 2016

\begin{abstract}
In this contribution, reduced graphene oxide-gold nanoparticles nanocomposite (RGO-AuNPs) was synthesized using electrochemical reduction of graphene oxide (GO) at an indium tin oxide (ITO) electrode followed by an electrodeposition process of loading AuNPs on its surface. The electrochemical reduction and deposition progress were characterized by a various technique including SEM, XRD, UV-vis spectroscopy and Raman spectroscopy. The performance of RGO-AuNPs show a reversible electrochemical property and could be successfully applied as pseudocapacitor electrodes with an outstanding stability. A high specific capacity of $288 \mathrm{~F} / \mathrm{g}$ at a high current density of $28 \mathrm{~A} / \mathrm{g}$ was obtained in the electrochemical investigation, which shows greatly enhanced performance for supercapacitor applications.
\end{abstract}

Keywords: Reduced graphene oxide; Electrochemical; Au nanoparticles; Supercapacitor

\section{$\underline{\text { FULL TEXT }}$}

(C) 2016 The Authors. Published by ESG (www.electrochemsci.org). This article is an open access article distributed under the terms and conditions of the Creative Commons Attribution license (http://creativecommons.org/licenses/by/4.0/). 